\title{
Familial primary hypomagnesemia with normocalcuria
}

INSERM

\section{Source}

INSERM. (1999). Orphanet: an online rare disease and orphan drug data base. Familial primary hypomagnesemia with normocalcuria. ORPHA:306522

Familial primary hypomagnesemia with normocalcuria (FPHN) is a form of familial primary hypomagnesemia (FPH; see this term) which is characterized by low magnesium values but normal calcium values in the serum. The disorder consists of three distinct forms which are: autosomal recessive primary hypomagnesemia with normocalcuria and hypocalcemia (ARPHN), familial primary hypomagnesemia with normocalcuria and normocalcemia (FPHNN) and isolated autosomal dominant hypomagnesemia, Glaudemans type (see these terms). 